\title{
Dynamics of Epidemiological Indications of Epilepsy Prevalence, Morbidity and Disability among Children in Kharkiv Region, Ukraine
}

\author{
Tetyana A Litovchenko ${ }^{1}$, Andriy E Dubenko ${ }^{2}$, Olga Yu Sukhonosova ${ }^{1}$ and Anna A Voitiuk ${ }^{1 *}$ \\ ${ }^{1}$ Department of Neurology and Child Neurology, Ukraine \\ ${ }^{2}$ Institute of Neurology, Psychiatry and Narcology of the AMS of Ukraine, Ukraine
}

*Corresponding author: Anna A Voitiuk, Department of Neurology and Child

Neurology, Kharkiv Medical Academy of Postgraduate Education, Kharkiv, Ukraine.

Received Date: March 29, 2019

Published Date: April 09, 2019

\section{Introduction}

According to the World Health Organization, epilepsy is one of the most common diseases of the central nervous system, which affects 0.5 to $2 \%$ of the entire population. Epilepsy prevalence in developed countries is 5-10 cases per 1,000 capita. According to the results of population studies conducted in developed countries, the incidence of epilepsy varies from 0.28 to 0.53 per 1,000 capita. There are discrepancies between prevalence and incidence of epilepsy in Europe and Ukraine [1], as well as the heterogeneity of prevalence and incidence of epilepsy in various regions of Ukraine: the prevalence of 4.28 per 1,000 children in Chernivtsi region to 2.47 in Khmelnytsky region $[1,2]$.

\section{Aim}

The purpose of the work is to carry out a population-statistical study of epilepsy among children in Kharkov region, Ukraine by registering and comparing the results with national and international indicators.

\section{Materials and Methods}

For the study the information from medical documentation was used: outpatient cards, the patient's clinical record. The primary material was collected by filling in a specially designed epilepsy registration card, as approved reporting forms showing general figures of prevalence, incidence and disability of children with a particular pathology do not give an idea of the etiology, pathogenesis, pathomorphosis of the disease, gender and age composition of patients. Based on the data obtained, a register of patients with paroxysmal conditions was created, which is cumulative for surveillance study. As of 01.01.17, 1301 children were included into the register, which allows monitoring of not only epidemiological, but also clinical, and paraclinical indicators, as well as the effectiveness of treatment and the level of patients' socialization. However, in this article, we analyze only epidemiological indicators, namely the prevalence and incidence. The data obtained are specified with the help of the reporting forms approved by the Order of the Health Ministry of Ukraine of 10.07.2007 № 378 in agreement with the State Statistics Committee of Ukraine (indicators for forms Nos. 12 and 19). For the comparative analysis, the statistical data of the last 5 years are used.

Kharkiv region is located in the north-east of Ukraine. The area is $31415 \mathrm{~km}^{2}$ (5.2\% of the territory of Ukraine). In terms of area, the region occupies the fourth place in Ukraine. The length: from north to south $-210 \mathrm{~km}$, from east to west - $220 \mathrm{~km}$. The population of the region according to the State Statistics Service is 2,715,666 people $(6 \%$ of the population of Ukraine, the third place in Ukraine), including urban population - 2180947 people (80.4\%), rural population $-534,719$ people $(19,6 \%)$. The population growth is due to the migration increase of 15125 people. Kharkov region is one of the most urbanized in Ukraine. There are 27 districts in Kharkov region (in this indicator the region takes the first place in Ukraine alongside with Vinnytsia region). The number of children's population of Kharkiv region in 2011 was 415,618 people, 2012 413718, 2013 - 416442, 2014 - 418984, 2015 - 422956 [3].

The prevalence of the disease is the number of all reported cases in a given population. The prevalence of epilepsy in Ukraine is 23225 children-3.05\%, exceeding the prevalence of infantile cerebral palsy, neuroinfection. 


\section{Result}

Kharkiv region ranks 14th among all regions of Ukraine in terms of epilepsy prevalence, the index for Kharkiv region is 3.43 per 1,000 children. The prevalence of epilepsy does not differ between the urban and rural population of Kharkiv region (the average value for 5 years is 3.204 per 1000 capita of both urban and rural children's population). The prevalence of epilepsy in Kharkiv region and Ukraine for 2011-2015 is presented in Table 1 , according to which it can be concluded that the prevalence of epilepsy has increased in the last 2 years (Table 1 ).

Table 1: The prevalence of epilepsy in the Kharkiv region and Ukraine in 2011-2015.

\begin{tabular}{|c|c|c|c|c|c|c|c|c|c|c|}
\hline & \multicolumn{2}{|c|}{2011} & \multicolumn{2}{|c|}{2012} & \multicolumn{2}{|c|}{2013} & \multicolumn{2}{|c|}{2014} & \multicolumn{2}{|c|}{2015} \\
\hline & 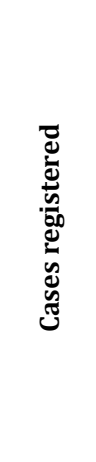 & 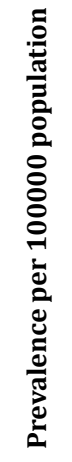 & 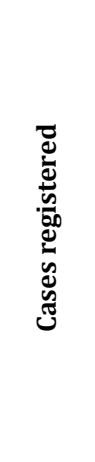 & 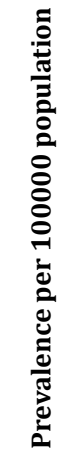 & 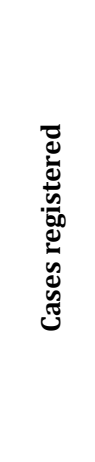 & 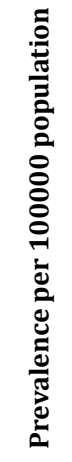 & 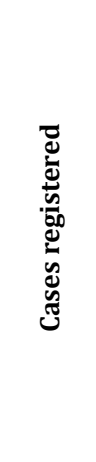 & 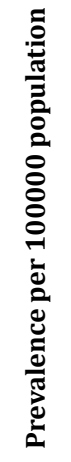 & 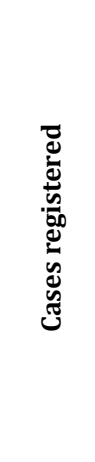 & 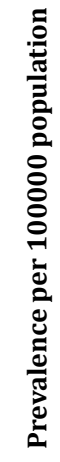 \\
\hline Kharkiv region & 1301 & 3,13 & 1310 & 3,17 & 1295 & 3,11 & 1345 & 3,21 & 1451 & 3,43 \\
\hline Ukraine & 25695 & 3,21 & 25802 & 3,24 & 25933 & 3,25 & 22549 & 2,97 & 23225 & 3,05 \\
\hline
\end{tabular}

\section{Discussion}

The epilepsy prevalence is 4-6 per 1000 capita. Studies conducted in various countries show epilepsy prevalence rates of 1.5 in Japan, 2.3 in Norway per 1000 capita, up to 6.0 in the United Kingdom, and 6.7 in the United States. The prevalence of epilepsy in developing countries is much higher (in some cases, 4-5 times) than in industrialized countries. The epilepsy prevalence in the CIS countries ranged from 1.1 to 5-6 per 1000 capita [1.4]

The official statistics may not correspond to the actual number of patients with epilepsy diagnosis, for instance, in some cases of symptomatic epilepsy it is not recorded statistically, but the underlying disease that led to the development of epilepsy is registered. Another advantage of the register is in the registration of other paroxysmal conditions, for example, febrile seizures, which according to different authors are related to the risk factors of epilepsy development. According to the register data of 2015, febrile convulsions were recorded in 62 children, 53\% of which were then transformed into epilepsy. Therefore, the register data can contribute to the early identification of risk factors for epilepsy, monitoring patients and secondary prevention of epilepsy. Morbidity is the incidence of new, first-reported cases of the disease in the population in a particular year.

The incidence of epilepsy in Ukraine among children aged 0-17 years is $0.43 \%$ (3,306 children). According to the incidence of epilepsy among children population (0-17 years), Kharkiv region ranks 17th among all regions of Ukraine [2]. The incidence of epilepsy among children in Kharkov region and Ukraine in 20112015 are presented in Table 2.

Table 2: The incidence of epilepsy among children in Kharkov region and Ukraine in 2011-2015.

\begin{tabular}{|c|c|c|c|c|c|c|c|c|c|c|}
\hline & \multicolumn{2}{|c|}{2011} & \multicolumn{2}{|c|}{2012} & \multicolumn{2}{|c|}{2013} & \multicolumn{2}{|c|}{2014} & \multicolumn{2}{|c|}{2015} \\
\hline & 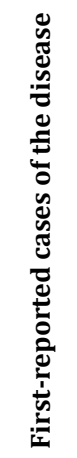 & 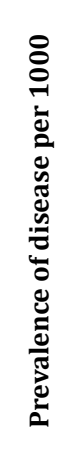 & 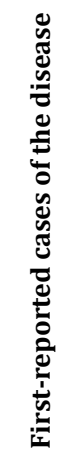 & 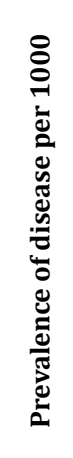 & 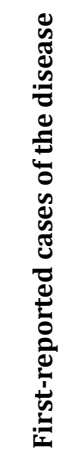 & 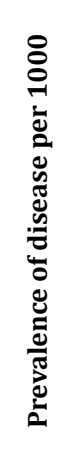 & 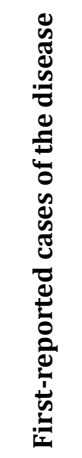 & 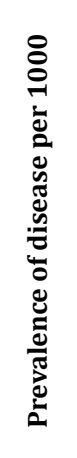 & 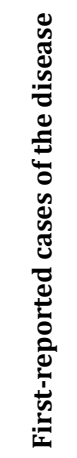 & 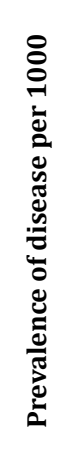 \\
\hline Kharkiv region & 132 & 0,67 & 99 & 0,5 & 105 & 0,53 & 89 & 0,44 & 114 & 0,56 \\
\hline Ukraine & 3971 & 0,5 & 3861 & 0,48 & 3579 & 0,45 & 3128 & 0,41 & 3306 & 0,43 \\
\hline
\end{tabular}

It should be noted that there was a significant prevalence of morbidity among urban population until 2014. However, in 2015 the difference between the incidence of epilepsy among the population of the city and regions was not recorded, which can be explained by migration of the population mainly to the districts of the region. 16 children with epilepsy from other regions migrated to Kharkov 
region. In the world, the incidence of epilepsy varies from 11 to 190 per 100,000 of child population, making up in Denmark 39, Great Britain 52-70, Germany 50, Italy 80-100, Sweden 82, Norway 72, Chile 114, Ecuador 190 per 100,000 children [4,5].
Thus, the incidence of epilepsy in Kharkov region is higher than in Ukraine. However, in general, it is lower than in developed European countries. The distribution of epilepsy patients by age and gender, according to the compiled register, is given in Table 3.

Table 3: Distribution of epilepsy patients by age and gender.

\begin{tabular}{|c|c|c|c|c|c|c|}
\hline \multirow{2}{*}{ Age } & \multicolumn{2}{|c|}{ Girls } & \multicolumn{2}{|c|}{ Boys } & \multicolumn{2}{|c|}{ Total } \\
\hline & Number of the sick & $\%$ & Number of the sick & $\%$ & Number of the sick & $\%$ \\
\hline 1-12 months & 34 & 49 & 35 & 51 & 69 & 5 \\
\hline 1-6 years & 121 & 46 & 141 & 54 & 262 & 20 \\
\hline 6-14 years & 208 & 52 & 193 & 48 & 401 & 31 \\
\hline $14-17$ years & 324 & 57 & 245 & 43 & 569 & 44 \\
\hline Total & 687 & 53 & 614 & 47 & 1301 & 100 \\
\hline
\end{tabular}

The table shows that the greatest prevalence of the disease is years. The onset-age distribution in boys and girls with epilepsy as recorded in boys under 6 years old, and then in girls aged 14-17 a percentage of each age group is shown in Table 4.

Table 4: The onset-age distribution in patients with epilepsy by gender in different age groups.

\begin{tabular}{|c|c|c|c|c|c|c|}
\hline \multirow{2}{*}{ Age } & \multicolumn{2}{|c|}{ Girls } & \multicolumn{2}{|c|}{ Boys } & \multicolumn{2}{|c|}{ Total } \\
\hline & Number of the sick & $\%$ & Number of the sick & $\%$ & Number of the sick & $\%$ \\
\hline 1-12 months & 99 & 49 & 102 & 51 & 201 & 15 \\
\hline 1-6 years & 231 & 47 & 264 & 53 & 495 & 38 \\
\hline 6-14 years & 273 & 60 & 185 & 40 & 458 & 35 \\
\hline $14-17$ years & 84 & 57 & 63 & 43 & 147 & 11 \\
\hline Total & 687 & 53 & 614 & 47 & 1301 & 100 \\
\hline
\end{tabular}

Analyzing the obtained data presented in Table 5, we can say that the maximum incidence of epilepsy falls on the age groups 1-6 and 6-14 years. Girls predominate at the age of 6-14, which can be explained by pre-pubertal age, and in boys 1-6 years old, which can be explained by greater activity, frequent craniocerebral trauma. Symptomatic epilepsies were recorded in $61 \%$ of patients, idiopathic - in $27 \%$, cryptogenic - in $12 \%$ of cases. The distribution of various forms of epilepsy is presented in Table 5, from which it can be seen that symptomatic epilepsy is observed equally often

Table 5: Gender distribution of patients with different forms of epilepsy.

\begin{tabular}{|c|c|c|c|c|c|c|}
\hline \multirow{2}{*}{ Type of Epilepsy } & \multicolumn{2}{|c|}{ Girls } & \multicolumn{2}{c|}{ Boys } & \multicolumn{2}{c|}{ Total } \\
\cline { 2 - 7 } & Number of the sick & $\%$ & Number of the sick & $\%$ & 52 & 793 \\
\hline Symptomatic & 385 & 48 & 408 & 29 & 352 & 27 \\
\hline Idiopathic & 251 & 71 & 101 & 68 & 156 & 12 \\
\hline Cryptogenous & 51 & 32 & 105 & & 1301 & 100 \\
\hline Total & 687 & & 614 & & Number of the sick & \\
\hline
\end{tabular}

The register data made it possible to analyze the medical and social status of children with epilepsy in different age groups.

The greatest number of socially-maladjusted children is between the ages of 7 and 14, i.e. they are school-aged children. These data are necessary for calculating the provision of inclusive education for children with epilepsy in comprehensive schools. About 300 children in Kharkov region require such education. In 2011, disabled children with epilepsy accounted for $38.36 \%$ of all epilepsy patients, in $2012-32.9 \%$, in $2013-31.45 \%$, in $2014-$ $31.45 \%$, in $2015-29.42 \%$. This indicates that the monitoring of in boys and girls, idiopathic forms are more commoearn in girls, and cryptogenic ones - in boys. Etiological factors of symptomatic epilepsy are: perinatal lesions of the central nervous system $28 \%$, congenital anomalies of the CNS - 24\%, neuroinfections - $8 \%$, craniocerebral trauma $-14 \%$, brain neoplasms $-2 \%$, phacomatosis - $1 \%$. According to children's disability indicators Kharkiv region ranks seventh in Ukraine. The epilepsy disability indicators among the children of Kharkiv region in 2011-15 are presented in Table 5. 
characteristics and more in-depth studies of the problem of children's epilepsy throughout Ukraine. Reliable epidemiological indicators, in their turn, will make it possible to improve the system of rendering specialized medical care to children with epilepsy, carry out a pharmaco-economic analysis, calculation and estimation of the costs for patients' treatment, which is especially important in the framework of the health care system reformation. Thus, the compilation of patients' registers with epilepsy is one of the most urgent tasks to optimize the provision of medical care to patients.

\section{Acknowledgement}

None.

\section{Conflict of Interest}

No conflict of interest.

\section{References}

1. Martynyuk V Yu (2015) Analysis of the Child Neurological Service of Ukraine for 2015. 25s

2. Statistical and analytical directory of the Ministry of Health "Providing medical care for psychiatry, neurology and neurosurgery for children 0-17 years in health care institutions located in the management of the Ministry of Health of Ukraine", Editor-in-chief Golubchikov MV

3. The basic indicators of health of the population and activities of the health care institutions of the Kharkiv region for 2006 - 2015 Establishment - the developer: KOZZ "Kharkiv Regional Information and Analytical Center of Medical Statistics" of the Department of Health Protection of the Kharkiv Regional State Administration

4. Banerjee PN (2009) The descriptive epidemiology of epilepsy. In: PN Banerjee, D Filippi, W Clen Hauser (Eds.), Epilepsy Res vol 85: 31-45.

5. Prasad A, Corbett B (2017) A national profile of neurodevelopmental disabilities in Canadian children: data from the National Longitudinal Study of Children and Youth. Materials of the 32nd International epilepsy congress, Barcelona, Spain $2^{\text {nd }}$. 